\title{
Influencia alemana en la reforma de las Escuelas Normales de Preceptores y Preceptoras en el centro sur de Chile, 1883-1920
}

\author{
The German Influence on the Reform of the Normal Schools for female and \\ male Preceptors in South Central Chile, 1883-1920
}

Influência alemã na reforma das Escolas Normais de Preceptores e

Preceptoras no centro sul do Chile, 1883-1920

\author{
Juan Mansilla Sepúlveda ${ }^{2}$ \\ Universidad Católica de Temuco, Chile \\ Grupo de investigacion HISULA - UPTC
}

Recepción: 12/03/2018

Evaluación: 05/05/2018

Aceptación: 29/06/2018

Artículo de investigación - Reflexión

DOI: 0.19053/01227238.8574

\section{RESUMEN}

Este artículo estudia la influencia de la pedagogía alemana en la reforma a la instrucción de profesores y profesoras en las Escuelas Normales que impulsaron los Gobiernos liberales a fines del siglo xIx en Chile. Las visitas a Alemania realizadas principalmente por Valentín Letelier Madariaga y José Abelardo Núñez les permitieron convencerse de la superioridad de los métodos germanos y la necesidad de otorgar a la pedagogía chilena un estatus científico, a imagen y semejanza de la cultura europea occidental y positivista. Con el análisis teórico documental que se realiza se pretende comprender la dinámica que adquirió la presencia ideológica y cultural alemana en el proyecto Estado-Nación pensado y soñado por los grupos dirigentes oligárquicos de Chile a partir de la formación de preceptores y preceptoras. El método fue cualitativo-descriptivo con un diseño historio-

$1 \quad$ El artículo presenta resultados del Proyecto de investigación Fondecyt CONICYT/FONDECYT Regular n. ${ }^{\circ} 1160409$ y del Proyecto de investigación Formación docente y practica pedagógica investigativa de los maestr@s de ciencias sociales de las Escuelas Normales Superiores (ens) programa de formación complementaria (PFC) en convenio con la Universidad Pedagógica y Tecnológica de Colombia - UPTC 2008 - 2016 código SGI 2197. desarrollado por el grupo de investigación "Historia y Prospectiva de la Universidad Latinoamericana”. HISULA y financiado por laVicerrectoria de investigaciones de la UPTC.

2 Profesor de Historia, Geografía, y Ciencias Sociales. Magíster en Desarrollo Regional y Local. Doctor en Filosofía y Letras. Académico de la Facultad de Educación, Universidad Católica de Temuco, integrante del grupo de investigacion HISULA adscrito a la UPTC. Correo electronico: jmansilla@uct.cl 
gráfico, el cual se desarrolló a partir de la triangulación metodológica entre fuentes primarias y secundarias. Los resultados pueden contribuir a promover el interés por estudiar un campo inexplorado por la investigación educativa en Chile: la enorme influencia alemana en los inicios de la instalación de la escuela normal en el centro sur de Chile.

Palabras clave: Revista Historia de la Educación Latinoamericana; preceptores; Alemania; Araucanía.

\section{ABSTRACT}

This article studies the influence of the German pedagogy in the teachers training reform of the Normal Schools promoted by the liberal governments at the end of the 19th century in Chile. The visits of Valentín Letelier Madariaga and José Abelardo Núñez to Germany convinced them about the superiority of Germanic methods and the need to provide the Chilean pedagogy with a scientific status, in the image and likeness of Western European and positivist culture. This documentary theoretical analysis aims to understand the dynamics of the German ideological and cultural presence in the Nation-State project, thought and dreamed, by the oligarchical leading groups of Chile based on the formation of female and male preceptors. The method was qualitative-descriptive with a historiographic design developed from the methodological triangulation between primary and secondary sources. The results of this work can stimulate the interest to study an unexplored field in the Chilean educational research: the vast German influence at the begin- ning of the installation of the Normal School in South-central Chile.

Keywords: Journal History of Latin American Education; preceptors; Germany; Araucanía

\section{RESUMO}

Este artigo estuda a influência da pedagogia alemã na reforma da instrução de professores e professoras nas Escolas Normais que impulsionaram os governos liberais nos fins do século XIX no Chile. As visitas à Alemanha realizadas principalmente por Valentín Letelier Madariaga e José Abelardo Núñez lhes permitiram convencer-se da superioridade dos métodos germânicos e da necessidade de outorgar a pedagogia chilena a um status científico, à imagem e semelhança da cultura europeia ocidental e positivista. Por meio de uma análise teórico documental se pretende compreender a dinâmica que adquiriu a presença ideológica e cultural no projeto Estado-Nação, pensado e sonhado pelos grupos dirigentes oligárquicos do Chile a partir da formação de preceptores e preceptoras. O método usado foi qualitativo-descritivo com um recorte historiográfico, que se desenvolveu a partir da triangulação metodológica entre fontes primarias e secundárias. Os resultados podem contribuir para promover o interesse por estudar um campo inexplorado pela pesquisa educativa no Chile: a enorme influência alemã nos inícios da instalação da escola normal no centro sul do Chile.

Palavras-chave: Revista História da Educação Latino-americana; preceptores; Alemanha; Araucânia.

\section{INTRODUCCIÓN}

El trabajo se plantea a partir del proyecto de investigación que hemos desarrollado desde la línea de historia de la educación en la Facultad de Educación de la Universidad Católica de Temuco, en el marco del Proyecto Fondecyt Regular denominado "Historia y memoria de la escuela monocultural en la Arau- 
canía (siglos xix y xx)". De este modo, la pregunta que orienta la investigación: ¿Cómo se instaló, implementó y consolidó la influencia alemana en la reforma de las Escuelas Normales de Preceptores y Preceptoras en el centro sur de Chile en el periodo 1883-1920? se ubica en un periodo fundacional en la historia de la instalación del Estado-nación en Chile. En este sentido, cuando situamos el estudio en el "centro sur de Chile" estamos ubicados en la Araucanía. El hito temporal que da inicio a la problematización corresponde al año 1883, cuando se produce la refundación de Villarrica en pleno territorio mapuche, actual región de la Araucanía, después de la derrota geopolítica y militar de ese ancestral pueblo originario ante el Ejército de Chile, que por cierto acababa de salir victorioso en la Guerra del Pacífico; y 1920 corresponde al año en que comenzó la implementación de la Ley de Instrucción Primaria Obligatoria en Chile. Desde este contexto, los cambios políticos, sociales, geográficos y culturales sucedidos en los primeros años del siglo xx fueron un desafío a que los grupos dirigentes lograran vehiculizar e impregnar desde la escuela el nacionalismo. El ocuparse de este reto poco a poco le fue otorgando un mayor valor a la educación y labor docente. Una yuxtaposición híbrida entre escuela y bandera, profesores y héroes, libros escolares, silabarios, biblias, himnos patrios, civilización y barbarie, médicos escolares, entre otros, fueron aportando insumos para la sedimentación de sentidos de un nacionalismo robusto. $Y$ en este escenario las Escuelas Normales desarrollaron un rol primordial, y ese liderazgo, al menos en el periodo estudiado, lo asumieron de manera predominante preceptores alemanes.

Por lo tanto, se justificó el estudio para relevar la reflexión historiográfica, bio-política y pedagógica sobre la influencia de culturas, racionalidades y estrategias foráneas en conformación de los idearios pedagógicos que se instalaron en Chile a fines del siglo xIx y comienzos del xx, en especial alemanes, a través de la formación de maestros y maestras en las Escuelas Normales. En este mismo campo, la situación es compleja en el territorio en el cual se instalaron dichas escuelas, tal es el caso de la Escuela Normal de Valdivia, fundada en 1898, Victoria en 1906 y Angol en 1908, en el corazón de la Araucanía. Asimismo, no existe suficiente evidencia empírica ni investigaciones que hayan estudiado la influencia alemana en la instalación de las Escuelas Normales en Chile y en la Araucanía en el periodo abordado, lo que nos motiva a desarrollar una investigación de esta naturaleza. La presencia de alemanes en el centro sur de Chile conllevó el inicio de un sutil nuevo proceso de colonización, basado en el currículum implementado en las Escuelas Normales y en las escuelas, el cual tenía como fin último lograr la asimilación y aculturación de los niños mapuche a la cultura occidental chilena a partir de la enseñanza de valores patrios y del idioma castellano.

La formación de profesores en Chile nace en el siglo xix bajo una forma rudimentaria de instrucción, descrita por algunos como la etapa pre-profesional ${ }^{3}$, en la que el maestro se forma en el oficio a través de un aprendizaje práctico y avanza a través de ensayos y errores. Las Escuelas Normales chilenas requerían que

3 Andy Hargreaves, "Cuatro edades del profesionalismo y del aprendizaje profesional", en La formación de profesores. Perspectiva y experiencias, ed. por B. Ávalos \& M. E. Nordenflycht (Santiago: Aula XXI/Santillana, 1999), 138-154. 
el profesor, en este caso de nivel primario, dominara aquello que mínimamente necesitaran sus alumnos para lograr metas específicas: leer, escribir, contar, entender principios básicos del entorno natural, la historia y geografía del país. Cabe decir que el presidente de la República de Chile, Manuel Montt, nombraría a Domingo Sarmiento director de la Escuela Normal el 20 de enero de 1842 con la asignación de mil doscientos pesos anuales. Su primer encargo fue arreglar los cuadros de lectura y acomodar el local ${ }^{4}$ donde funcionaría.

Lo que implicaba la carrera de "ser profesor" evoluciona con el establecimiento de nuevas Escuelas Normales, el aumento del currículum de formación y el haber fundado, a fines del siglo xIX, el Instituto Pedagógico para profesores secundarios ${ }^{5}$.

Desde 1833 (año de la primera Constitución de la República) hasta 1881 (fundación de Temuco y derrota del pueblo mapuche ante el Ejército chileno) la actividad política educativa del Estado se orientó a difundir, traducir, adaptar al medio chileno y hacer leer obras de autores franceses, así como el ejercicio docente de innumerables educadores franceses y al tiempo con lo anterior el arribo y presencia de congregaciones religiosas de origen francés consagradas a la enseñanza ${ }^{6}$. Esto legitima la idea asociada al complejo proceso de transferencia cultural que vivió Chile en ese periodo. Francia se transformó en el más perfecto y prestigioso modelo de sociedad, y por consiguiente, en el núcleo cultural que cautivó, particularmente, a los grupos más pudientes de la sociedad, aristocráticos y burgueses que buscaron imitar y hacer suyos aquel ethos europeo, al límite de experimentar un verdadero proceso de aburguesamiento, afrancesamiento y de francomanía ${ }^{7}$.

Después de la Guerra del Pacífico (1879-1883) y de la incorporación forzosa de la Araucanía al territorio de Chile, el país transitó hacia un escenario caracterizado por novedosas tendencias en torno a la historia de la educación, que fueron configurando y sedimentando otras representaciones del mundo, un nuevo imaginario colectivo a partir de los complejos procesos de recepción, transferencia, apropiación social y cultural de componentes simbólicos exógenos, esta vez desde una matriz cultural epistémica germana ${ }^{8}$. El imaginario que, trazado

4 Sergio Vergara Quiroz, estudio, selección y notas, Manuel Montt y Domingo F. Sarmiento. Epistolario 1833-1888. Fuentes para la historia de la República, vol. xiv. (Santiago: Dibam y Centro de Investigación Diego Barros Arana, 1999), 53.

5 Beatrice Ávalos Davidson, “La profesión docente en Chile a más de 150 años de su primera institucionalización”, en Relatos para la educación en el bicentenario (Santiago: Universidad de Chile, Universidad Católica, 2010), 152.

6 Juan Conejeros Maldonado, La influencia cultural francesa en la educación chilena 1840-1880 (Santiago: Universidad Católica Silva Henríquez, 1999), 31.

7 Sergio Villalobos Rivera, Origen y ascenso de la burguesía chilena (Santiago: Editorial Universitaria, 1987), 78, 31.

8 Juan Conejeros Maldonado, De la francomanía al embrujo alemán. Alcances en torno al rol de los agentes mediatizadores en el proceso de transferencia cultural alemana en la educación chilena (1880-1910). (Santiago: Ediciones Universidad Tecnológica Metropolitana, 2015), 36 . 


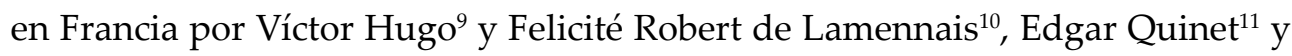
Jules Michelet ${ }^{12}$, se había anidado en el imaginario colectivo nacional de las elites ilustradas chilenas, comenzará a verse mermado después de los trascendentales acontecimientos de la guerra franco prusiana ocurridos entre el 19 de julio de 1870 y el 10 de mayo de 1871, que enfrentó al Segundo Imperio franco con el Reino de Prusia. En este escenario la elite intelectual y política chilena comenzará a fijar su atención en este nuevo referente cultural exógeno: Alemania ${ }^{13}$.

En consecuencia, el proceso político, histórico y social que vive Chile en la segunda mitad del siglo xix condiciona el rol de la educación en la configuración de lo que se ha denominado "estado en forma". Aparecen en este escenario relevantes figuras públicas, tales como Valentín Letelier, Claudio Matte y José Abelardo Núñez, quienes van a realizar diversos viajes a Alemania entre 1870 y 1890, transformándose en agentes mediadores de un intenso, profundo y complejo proceso de transferencia cultural que experimentará Chile entre 1880 y 1910, focalizado en las nuevas tendencias de ideas pedagógicas vigentes en Europa, muchas de ellas deudoras del pensamiento herbartiano, paradigmas que acogerán los grupos dirigentes de la educación chilena con excesivo entusiasmo, debido a que - según sus percepciones - , representaban el progreso y

9 Víctor Hugo (1802-1885) fue un intelectual francés y representa la cima más elevada del Romanticismo. Cultivó todos los géneros literarios: poesía (toda su vida, incluso en su ancianidad, cantó con incomparables versos la hermosa experiencia de ser abuelo), dramaturgia (durante su juventud), novela (sobre todo en su madurez y senectud). Fue pensador, poeta y político. Cultivó la novela romántica, la histórica y la inspirada en el realismo social. Su vida está llena de paradojas. Hijo de un general del ejército napoleónico, monárquico en su juventud, recibió todos los honores durante la Restauración y durante el reinado de Luis Felipe. Aunque fue elegido diputado por las derechas en 1848, desde muy temprano evolucionó hacia la izquierda. Se enfrentó al golpe de Estado de 1851; perseguido, marcha al exilio por veinte años, tiempo en que no se cansa de fustigar a Napoleón iII. Retorna a Francia en 1870 y es elegido senador vitalicio. Arnoldo Mora Rodríguez, "En el bicentenario de su nacimiento: Víctor Hugo y la estética del romanticismo". Revista Comunicación, n. ${ }^{\circ} 2$ (2002): 5-6.

10 Filósofo, teólogo católico y político francés (1782-1854). Fue maestro de Francisco Bilbao, revolucionario intelectual chileno quien protagonizó, a los 21 años, uno de los mayores escándalos editoriales del siglo xix chileno: la publicación de Sociabilidad chilena, por la cual fue acusado de hereje, inmoral y sedicioso, lo que le valió la expulsión del Instituto nacional, donde estudiaba, y un vasto ataque en la prensa que logró unir en contra suya a prácticamente toda la intelectualidad chilena. El muchacho se vio en la necesidad de exiliarse e hizo el viaje iniciático a Francia, donde conoció Lamennais, en ese momento un apasionado defensor de la lucha anticolonial de Polonia y otras naciones sin Estado, y el ejemplo de Polonia lo llevará a reconciliarse con las demandas sociales de los movimientos políticos modernos. La creciente radicalización del sacerdote lo llevará a la ruptura con el papa en 1832, y luego a la escritura de "Palabras de un creyente", gran manifiesto radical al que Harold Laski se refirió con admiración como "una versión lírica del Manifiesto comunista", que prepara el camino para obras como El libro del pueblo y De la esclavitud moderna, que fue traducido por Bilbao. Rafael Mondragón Velázquez, "Anticolonialismo y socialismo de las periferias. Francisco Bilbao y la fundación de $L a$ Tribune des Peuples". Latinoamérica. Revista de Estudios Latinoamericanos, n. ${ }^{\circ} 56$ (2013): 105-139.

11 Historiador, escritor e intelectual francés (1803-1875). Fue protagonista en la revolución de 1848. Los conflictos con Napoleón II terminaron por conducirlo al exilio en 1852. Desde ese año y hasta 1872 permaneció en Bélgica y Suiza. Regresó a París en 1870. Fue uno de los más genuinos representantes de la historiografía francesa revolucionaria y crítica. Destacan las siguientes obras: Las revoluciones de Italia (1848-52), Historia de mis ideas (1858), Filosofía de la historia de Francia (1858), La Revolución (1865), France et Italie (1867), La cuestión romana ante la Historia (1867). El foco central del pensamiento de Quinet es el vasto debate entre las concordancias y contrariedades que se producen entre historia y filosofía. Como heredero del iluminismo, Quinet busca encontrar realizaciones en la historia francesa de los principios y valores que se configuraron en el siglo XviII. Arlenice Almeida da Silva, "Edgar Quinet e a filosofia da Revolução Francesa". Revista de História, n. ${ }^{\circ} 146$ (2002): 223-266.

12 Historiador francés (1798-1874). Desde 1839 hasta 1850 fue profesor de moral e historia en el Colegio de Francia, de donde fue destituido por problemas políticos. Si bien sus ideas políticas lo sumieron en una situación sumamente precaria, no claudicó. Propuso un nuevo período: el Renacimiento. Lo describió como el fin de la Edad Media, el comienzo de la mundialización, un paso al mundo moderno y el retorno al paganismo, la sensualidad y la libertad. Josefina Zoraida Vázquez, Historia de la historiografía (México: Ateneo, 1978), 108.

13 Si bien es cierto que a partir de 1880 existió una admiración por lo alemán generando una especie de "embrujamiento germánico", esta fijación por la cultura germana está tempranamente presente en algunos agentes de la elite liberal decimonónica, como Benjamín Vicuña Mackenna, Isidoro Errázuriz y Vicente Pérez Rosales, promotores de la inmigración alemana al sur de Chile. 
lo moderno ${ }^{14}$. Sarmiento había visitado diversos países de Europa, como Francia, España, Italia, Suiza, Austria, Alemania, Holanda, Bélgica e Inglaterra, así como Estados Unidos, Brasil y algunos de África, lugares todos donde conoció las experiencias pedagógicas principalmente sobre la educación primaria, educación de la mujer, y determinados métodos de enseñanza. Fruto de esa misión y de sus experiencias en el exterior fueron sus libros Educación popular y Viajes, publicados en $1849^{15}$.

Por tanto, la educación en Chile en el último tercio del siglo xIx transitó hacia un nuevo paradigma cultural y epistemológico, siempre buscando las respuestas y los modelos pedagógicos en Estados Unidos o Europa. Es el ocaso del ciclo de la influencia francesa que caracterizó de modo gravitante a la cultura iberoamericana de la post-independencia y, por cierto, a Chile, país que no pudo sustraerse a este fenómeno ${ }^{16}$. Esta importante tendencia cultural que caracteriza este periodo está marcada por la fuerte influencia del liberalismo europeo y el romanticismo, generando en los grupos dirigentes y la clase ilustrada de Chile una actitud que sobrevaloraba lo foráneo, lo que se expresó no solamente en la vida cotidiana (comida, vestuario, expresiones lingüísticas, fiestas, modas), sino, en el modelo educativo implementado.

El trabajo se presenta en tres apartados. En primera instancia se establece como objetivo central analizar el proceso de transferencia cultural y educativa de la pedagogía alemana a Chile a través de Valentín Letelier Madariaga, Claudio Matte y José Abelardo Núñez. Luego se estudia la presencia de los primeros profesores de origen alemán que llegaron a Chile y su influjo en las Escuelas Normales, y finalmente, las circunstancias que albergaron la temprana formación de preceptores y preceptoras en la Araucanía.

El corpus de este trabajo se desarrolló desde el método centrado en la historia social de la educación ${ }^{17}$, desde un diseño historiográfico, anclado en la tradición cualitativa. De este modo, el exhaustivo examen teórico realizado se sustenta en resultados de un proyecto de investigación prioritario patrocinado por Fondecyt/Conicyt-Chile. La propuesta final sistematiza datos recogidos a partir de triangular diferentes fuentes escritas revisadas en archivos en Temuco, Santiago y Berlín.

En líneas generales, se concluye que permanecen rasgos importantes de la influencia alemana en el currículo escolar chileno, asunto que ha sido abordada muy parcialmente de las investigaciones que abordan la historia de la educación en Chile. En este escenario, las Escuelas Normales se constituyeron en un nuevo espacio de frontera intercultural se produjo diferentes intersecciones ideológi-

14 Benjamín Silva Torrealba, "Historia social de la educación chilena", en Instalación, auge y crisis de la reforma alemana 1880 a 1920. Agentes escolares, t. 1 (Santiago: Ediciones Universidad Tecnológica Metropolitana, 2015), 43.

15 Javier Ocampo López, “Domingo Faustino Sarmiento. El Presidente de Argentina 'Maestro de América”, Revista Historia de la Educación Latinoamericana, n. ${ }^{\circ} 2$ (2000), 1-25.

16 Ricardo Krebs Wilckens y Cristian Gazmuri Riveros, La Revolución francesa y Chile (Santiago: Editorial Universitaria, 1990$), 102$.

17 Se toma de base lo indicado en José Pascual Mora García, Diana Soto Arango y José Rubens Lima Jardilino, "La historia de la educación en América Latina: Contribución y aportes de la Sociedad de Historia de la Educación Latinoamericana SHela (1994-2015)", Revista História da Educação, n. ${ }^{\circ}$ 51, vol. 21 (2017): 351-375. http://seer.ufrgs.br/index.php/asphe/issue/view/2822/ showToc 
cas, culturales y políticas que vivió la educación chilena a fines del siglo xIX y comienzos del siglo xx, con la pedagogía alemana como su principal referente.

\section{El impulso de Valentín Letelier Madariaga, Claudio Matte y José Abelardo Núñez}

Uno de los primeros agentes de este proceso fue Valentín Letelier Madariaga (1852-1919), destacado difusor de la filosofía positivista en el contexto chileno y defensor del Estado docente, la instrucción popular y la cultura científica europea $^{18}$. Letelier visitó Alemania en 1884 en su calidad de secretario de la Legación chilena en Berlín. Asombrado del valor y prestigio que lograba la pedagogía prusiana en Alemania y Europa Occidental, al amparo de las influyentes ideas de Wilhelm von Humboldt (1767-1835) y en particular de los planteamientos del pedagogo realista Johann Friedrich Herbart (1776-1841), Valentín Letelier difundirá y recomendará su urgente implementación en Chile, para de este modo transformar el sistema pedagógico al que consideraba "primitivo y obsoleto"19.

En este contexto Letelier será uno de principales impulsores de la reforma de la educación secundaria en Chile (Reforma del Liceo de Hombres, iniciada en 1883) denominada "Plan concéntrico", inspirada en el modelo pedagógico prusiano. En consecuencia, los estudios secundarios que habían tenido hasta entonces similitud con el liceo francés de principios del siglo XIX, ahora vienen a asemejarse al del real gimnasio alemán ${ }^{20}$. Este giro epistemológico, político y cultural traerá consecuencias gravitantes para la formación del profesorado en Chile. Asimismo, esta iniciativa reformista tensionó especialmente a las instituciones escolares dependientes de congregaciones religiosas católicas, que observaban con inquietud las nuevas improntas liberales, cientificistas y laicistas que se impulsaban desde el Estado hacia la sociedad chilena ${ }^{21}$.

Con este nuevo paradigma emergen otras categorías conceptuales para delimitar el telos de los discursos y prácticas pedagógicas, una de estas fue la noción de "formación" (Bildung ${ }^{22}$ ) del ser humano, concepción heredera de la visión humanista que Humboldt instaló en la reforma del sistema educativo prusiano de comienzos del siglo $\mathrm{XIX}^{23}$.

Además de los informes emitidos por Valentín Letelier, la influencia alemana en los procesos de formación en Chile se reforzó con la llegada de numerosos

18 Iván Jaksic Andrade, "Valentín Letelier: the Influence of positivism on Chilean Educational Thought”, Pensamiento Educativo, n. ${ }^{\circ} 46$ (2010): 127-145.

19 Gonzalo Vial Correa, Historia de Chile (1891-1920), vol. 1, La sociedad chilena en el cambio de siglo (Santiago: Editorial Santillana, 1981), 156.

20 Amanda Labarca, Historia de la enseñanza en Chile (Santiago: Imprenta Universitaria, 1939), 234.

21 María Muñoz Gomá y Abdón Cifuentes, "Visión de futuro. La orientación práctica de la enseñanza (1836-1928)", Pensamiento Educativo, n. ${ }^{\circ} 34$ (2004): 289.

22 La palabra alemana Bildung remite a imagen (Bild), modelo (Vorbild), imitación (Nachbild). Es una síntesis y, a la vez, una superación de Form (forma), de Kultur (cultura) y de Aufklärung (Ilustración). Michel Fabré, "Experiencia y formación: la Bildung". Revista Educación y Pedagogía, 23, n. 59 (2011):216.

23 Jean Château, Les Grands pédagogues (Paris: Puf, 1974), 299. 
profesores alemanes contratados por el Estado de Chile, los cuales provenían de los diversos Estados y regiones de la tierra germana: Prusia, Sajonia, Silesia, Renania, etcétera). En este escenario se fundará en 1889 el Instituto Pedagógico, institución encargada de la formación de profesores de enseñanza secundaria en Chile ${ }^{24}$.

En este contexto destaca la presencia e influencia del educador chileno Claudio Matte, quien en conjunto con Valentín Letelier recogió reglamentos, obras especiales, ordenanzas y diversos documentos durante su visita a Alemania ${ }^{25}$. En el Congreso Pedagógico de 1889 Claudio Matte, en particular, planteaba no transformar la escuela en una enseñanza de oficios con pretensiones meramente técnicas, porque la escuela no tenía como tarea formar obreros ${ }^{26}$. El sello de los planteamientos de esta propuesta de renovación pedagógica, "embrujo alemán", significó un desarrollo en la formación docente inaugurada con el arribo a Chile, con el objeto de dirigir las Escuelas Normales, de instructores e instructoras de origen germano ${ }^{27}$. Por mediación de Matte, entre 1881 y 1905 la editorial alemana Brockhaus imprimió alrededor de un millón de libros para instituciones educativas chilenas. Lo que Matte y Núñez iniciaron como un mecanismo para financiar sus estancias en Europa se convirtió enseguida en una descomunal empresa de nacionalización cultural. Ánimo de lucro, patriotismo, nacionalismo y capitalismo internacional se conjugan en el fenómeno de estas ediciones alemanas ${ }^{28}$. Es así como aparece la primera edición del Silabario Matte en 1902. Según el historiador conservador Gonzalo Vial, gracias a Claudio Matte los alemanes introdujeron disciplina severa, pero digna; crearon o enfatizaron cursos de dibujo, canto, trabajos manuales, gimnasia, conocimiento de la naturaleza y, sobre todo, dieron al trabajo docente un fundamento científico: el método pedagógico de Johan Friederich Herbart ${ }^{29}$. El viaje realizado a Alemania en 1888 en búsqueda de profesores para formar educadores para la educación secundaria, se hizo en un contexto en el que había cerca de setenta liceos fiscales y ciento veintidós particulares ${ }^{30}$.

Otro agente relevante en este proceso de transferencia cultural de matriz germana fue José Abelardo Núñez ${ }^{31}$. En 1878 el Gobierno del presidente Aníbal

24 Iván Núñez Prieto, "La formación de los docentes. Notas históricas”, en Beatrice Ávalos, Profesores para Chile. Historia de un proyecto (Santiago: Ministerio de Educación, 2002), 114.

25 Biblioteca Nacional de Chile (вNCH), Santiago de Chile. José Toribio Medina, Fondo Histórico y Bibliográfico José Toribio Medina, vol. 8, Documento 113 .

26 José Abelardo Núñez, Congreso Nacional Pedagógico. Resumen de las discusiones, actas y memorias, publicación oficial (Santiago, Imprenta Nacional, 1890), 14.

27 Carolina Figueroa Cerna y Benjamín Silva Torrealba, "La demanda política de un actor educativo: el visitador de escuelas primarias Ramón López Pinto (Tarapacá, norte de Chile 1889-1907)”, Cuadernos de Historia, n. 34 (2011):1-29.

28 Rossana Cassigoli, "Sobre la presencia nazi en Chile", Acta sociológica, n. 61 (2013): 157-177.

29 Gonzalo Vial Correa, Historia de Chile, t. II (Santiago: Portada, 1981), 239.

30 Jaime Caiceo Escudero, "Orígenes y principales exponentes del laicismo, en su vertiente educativa, en Chile", Revista Historia da Educaçãn, n. ${ }^{\circ}$ 51(2017): 333-350.

31 De profesión abogado, ocupó diversos cargos públicos: fue miembro de la Sociedad de Instrucción Primaria, vicepresidente de la Comisión visitadora de Escuelas, visitador general de las Escuelas Normales, inspector general de Instrucción Primaria, director del Boletín de Educación. Luis Celis Muñoz, Educadores ilustres en la historia educacional chilena, siglos XVIII-XIX. (Santiago: Pontificia Universidad Católica de Chile), 78. 
Pinto encargó a José Abelardo Núñez, director de Enseñanza Primaria, la misión de visitar diversos centros educacionales en Europa y Estados Unidos, a fin de obtener un diagnóstico que permita saber el "estado de la cuestión". Después de varios años de viajes y de informes, en su rol de comisionado de Educación del Gobierno de Chile, emitió a José Ignacio Vergara, quien entonces se desempeñaba como ministro de Instrucción Pública del presidente Domingo Santa María, el primer informe fechado el 5 de noviembre de 1883 en el que sistematiza las observaciones y registros realizados tanto en Chile como en Europa, cuyo eje articulador fue el estado de las Escuelas Normales ${ }^{32}$.

José Abelardo Núñez quedó impresionado con la educación en Sajonia y Prusia, donde visitó el Seminario real para preceptoras (Das Königliche Seminar für Stadtschullerhrer), y el Seminario para preceptores (Seminar für Stadtschullerhrer) fundado por el barón von Fletcher, de Dresden.

En este orden de cosas, las cuestiones curriculares y didácticas, así como los principios teóricos y actividades prácticas que José Abelardo Núñez vivenció, le permitieron convencerse de la superioridad de la pedagogía germana. Asimismo, fue particularmente significativa la percepción que construyó a partir de la importancia que le atribuían las Escuelas Normales al conocimiento referido al reino de la naturaleza (naturkunde), y por añadidura, a las ciencias de la naturaleza, que a la vez era el campo disciplinario hegemónico, a propósito del positivismo decimonónico. Junto con las ciencias naturales, tuvo una impresión muy positiva del cultivo de las artes y la música. A su juicio, los estudiantes se moldeaban de tal modo que al final de su formación parecían verdaderos maestros "formados ya en la ciencia de enseñar". De la siguiente manera comenta esta percepción el comisionado chileno:

La disciplina escolar de aquellas escuelas, la manera como se dirijen las clases, el sistema de discusión constate entre alumnos i el profesor i los conocimientos tan jenerales como profundos que en esas discusiones revelaban poseer los normalistas, no pudieron menos de inspirarme, desde las primeras visitas a las escuelas normales, la más alta idea del estado en que se encontraba en Alemania la educación pública ${ }^{33}$.

Otra observación que planteó José Abelardo Núñez para evidenciar lo que presenció en su visita por Europa se refiere a la valoración social hacia los docentes. Desde su perspectiva y según lo que pudo constatar en las doce Escuelas Normales de Sajonia examinadas, el profesorado disfrutaba de una alta consideración, tanto así que los directores y el cuerpo docente de estas escuelas figuraban entre los más distinguidos profesores y hombres de letras del país ${ }^{34}$.

32 José Abelardo Núñez Murúa, Estudios sobre educación moderna: Organización de escuelas normales. (Santiago: Imprenta de la Librería Americana, 1883), 14.

33 Carta de José Abelardo Núñez a José Eugenio Vergara, ministro de Instrucción Pública de Chile, con fecha 9 de agosto de 1882.

34 Ibíd., 34. 
La percepción que fue sedimentándose en Occidente a partir de estos hechos, es que la pedagogía adquiría en Alemania un verdadero estatuto epistemológico de cientificidad y rigor, y de seguro esto caló hondamente en el espíritu de Núñez. Lo anterior se corrobora en las ideas que expone Jean-Pierre Blancpain, quien analizó el libro de José Abelardo Núñez Estudios sobre educación moderna, donde elogia a las escuelas prusiana y sajona, a las que compara con el modelo francés, y a la vez, levanta una crítica a este último por ser un prototipo de formación burgués e igualitario, y que solo se limita a confiar la eficacia de la instrucción y la enseñanza en la cultura del maestro ${ }^{35}$.

Desde esta perspectiva, el Gobierno chileno enviará en etapas sucesivas a egresados de las Escuelas Normales a perfeccionarse, de preferencia a Europa. Ellos retroalimentarán el sistema, vinculando su evolución futura a las raíces conocidas y acentuando las limitaciones que ya visualizaban en la enseñanza ${ }^{36}$. En este contexto, no se otorgó suficiente valoración a los problemas propios de Chile, como la educación rural, la educación intercultural o la educación popular.

La evaluación que hizo a los grupos dirigentes de Chile respecto a la evolución de las Escuelas Normales no era positiva. Se valoraba que el esfuerzo realizado en 1842 con la creación de la primera Escuela Normal de Preceptores, no estaba dando los frutos esperados:

(...) cerca de medio siglo ha pasado $i$, doloroso es decirlo, la enseñanza normal, si no ha decaído, ha permanecido estacionaria e ignorante de los progresos alcanzados por la educación moderna en este periodo de tiempo ${ }^{37}$.

El diagnóstico de José Abelardo Núñez era esclarecedor respecto al estado de situación de la educación chilena en general, y en particular a la situación coyuntural en que se encontraban las Escuelas Normales. En este orden de cosas plantea lo siguiente:

Nuestros establecimientos de enseñanza normal no corresponden actualmente ni a las necesidades del país, ni a los progresos de la escuela moderna, i es tiempo ya de modelar su organización de acuerdo con esas necesidades $i$ con los principios que reglan en el día el difícil arte de enseñar ${ }^{38}$.

Es posible afirmar que estas ideas planteadas por José Abelardo Núñez se fueron consolidando gradualmente y lograron convencer a otros agentes del medio nacional. El liderazgo que demostró fue gravitante en la reorganización de las escuelas normales, así como la actualización del ideario curricular y modernización de las instituciones formadoras de preceptores y preceptoras. Lo anterior se materializa en los importantes decretos del 26 de julio de 1883 . En

35 Jean Pierre Blancpain, Los alemanes en Chile (1816-1945). (Santiago: Universitaria), 102.

36 Luis Celis Muñoz, Historia de la educación chilena, siglos XVI a XIX. (Santiago: Universidad de Los Lagos, 2014 ), 197.

37 José Abelardo Núñez Murúa, op. cit., 302.

38 Ibíd. 
ellos se dispusieron mejoramientos de las escuelas elementales y superiores y a la vez se normó el servicio de los visitadores de las Escuelas "con un espíritu francamente moderno y disciplinado" ${ }^{\prime 39}$. En estos mismos decretos se derogan los "castigos corporales" 40 especialmente después de conocer las experiencias educativas de Pestalozzi, Ziller y Herbart, cuyas propuestas pedagógicas propagaban por Europa Occidental diversos principios asociados a un revisionismo de la metodología de los castigos físicos y de la disciplina conductual escolar ${ }^{41}$.

De hecho la prohibición del empleo del "guante" en los liceos públicos de Chile a fines del siglo xIx fue discutida en las más altas instancias como el Consejo de Educación Pública en la Universidad de Chile, en 1876. A partir de estos debates derivó el decreto del 8 de enero de 1877 al que se refiere Miguel Luis Amunátegui ${ }^{42}$. Entonces, al amparo de estas nuevas prescripciones normativas se apostó por legitimar un abordaje psicológico positivista respecto a la actuación de los estudiantes, lo que se refleja en la sobrevaloración de lo real, visible, medible y útil de la realidad. Esto derivó en un ethos que configuró el modo de pensar y otorgar el canon y estatus científico a las disciplinas que seguían este derrotero, con lo cual las ideas, percepciones y conciencia del mundo se naturalizaron en clave positivista, realista y pragmática ${ }^{43}$.

En la práctica esto significó "notas semanales y mensuales, inscripciones en el cuadro de honor para los mejores, privación de recreos para los más desordenados, reconvenciones y expulsiones para los más recalcitrantes y coscachos para los duros de cabeza" ${ }^{\prime 4}$. El propósito es instalar desde la escuela una sociedad disciplinaria. No obstante, no se deben confundir "norma" y "disciplina". Las disciplinas apuntan a los cuerpos con una función de adiestramiento; la norma es una medida, una manera de producir la medida común. Con la disciplina, según la lógica de la norma, la sombra llega a la luz. "En la disciplina, son los sujetos quienes han de ser vistos. Esta iluminación asegura el dominio del poder que se ejerce sobre ellos" 45 .

En el plano político-jurídico, la ley de 11 de octubre de 1883 resultó fundamental frente a la decisión de mejorar la educación pública en Chile. En ella no solo se autorizó que el presidente de la República (Domingo Santa María) invirtiera en la construcción de escuelas primarias, sino también (artículo n. ${ }^{\circ}$ 2) en la contratación de profesores en el extranjero, tanto varones como damas, que

39 Labarca, op. cit., 182.

40 Los instrumentos más utilizados para el castigo de faltas graves eran látigos de distintas formas como el chicote y el guante. Los profesores también disponían de la palmeta, una especie de raqueta para golpear las manos de los alumnos que cometían una falta. En este período también se utilizó la cabina de castigo así como ponerse de rodillas, a veces con los brazos en cruz y con un ladrillo en cada mano. Para faltas menores se acudía a coscorrones, tiradas de orejas o de patillas.

41 Juan Conejeros Maldonado, De la francomanía al embrujo alemán. Alcances en torno al rol de los agentes mediatizadores en el proceso de transferencia cultural alemana en la educación chilena (1880-1910).op.cit. 52.

42 Miguel Amunátegui Reyes, “Cómo y por qué se suprimió el castigo del 'guante’ en los colegios del Estado", Revista Chilena de Historia y Geografía, n. 39 (1920): 16-34.

43 Juan Mansilla Sepúlveda y Claudia Huaiquián Billeke, Logos y techné. Metodología de la investigación científica (Temuco: Universidad Mayor, 2015), 190.

44 Labarca, op. cit.

45 Michel Foucault, Vigilar y castigar. Nacimiento de la prisión (México: Siglo xxI, 1975), 110. 
pudieran prestar servicios en las Escuelas Normales primarias y superiores de Chile. Además, la ley, en su artículo $6 .^{\circ}{ }^{\circ}$ facultó al presidente para enviar a alumnos y maestros de la Escuela Normal de Preceptores a estudiar y perfeccionarse en el extranjero, principalmente a Alemania y Estados Unidos ${ }^{46}$.

En el inciso n. ${ }^{\circ} 6$ del artículo primero de este decreto se autorizó al presidente "para invertir hasta quince mil en las pensiones y gastos de viaje de los alumnos y maestros de la Escuela Normal de Preceptores que se envíen a Europa o Estados Unidos para desempeñar a su vuelta el cargo de preceptores de escuelas primarias". En este contexto, los primeros cinco normalistas fueron José Tadeo Sepúlveda, Juan Madrid, José María Muñoz Hermosilla, Emiliano Figueroa y Carlos Bosche.

José Abelardo Núñez regresó a Europa en 1884, esta vez encargado de cumplir los compromisos que establecía la ley en el sentido de visitar y estudiar centros paradigmáticos en la formación de profesores y elegir aquellos a donde se podrían enviar a los estudiantes chilenos y, en segundo lugar, contratar a profesores alemanes que ejercieran su enseñanza en Chile. De modo que es posible identificar diversos documentos y decretos con antecedentes relativos a la firma y prórroga, modificación y contratos de profesores en Europa para desempeñarse en las Escuelas Normales de Santiago. En esta lógica y desde entonces hasta los años veinte del siglo xx, las Escuelas Normales vivieron lo que podría denominarse su período "clásico" y se moldeó la imagen positiva hacia estas que ha permanecido en la memoria colectiva de los chilenos ${ }^{47}$.

\section{Primeros profesores de origen alemán que llegaron a Chile y su influjo en las Escuelas Normales}

Entre los primeros profesionales de origen alemán que llegaron a Chile se destacan los siguientes ${ }^{48}$ :

- B. Krüssel (1887). Profesor de dibujo a mano libre y aplicación industrial, proveniente de Hamburgo. El profesor se comprometió a prestar sus servicios al gobierno de la República en la Escuela Normal de Preceptores de Valparaíso. Se le indicó también que la enseñanza de dicho ramo sería durante 24 horas, distribuidas en los días de la semana. Por otra parte, el profesor se comprometió a estudiar con toda la posible consagración de la lengua española, en la que tendría que hacer las explicaciones necesarias para la enseñanza de su ramo. Su contrato fue por seis años ${ }^{49}$.

- Hermann H. Langer. Profesor de dibujo y aplicación industrial y de gimnástica. Fue contratado para ejercer el ramo de dibujo (18 horas semana-

46 Conejeros, op. cit., 53.

47 Iván Núñez Prieto, “Escuelas Normales: una historia larga y sorprendente. Chile (1842-1973)”, Pensamiento Educativo, n. ${ }^{\text {4 }}$ 46-47 (2010): 133-150.

48 Conejeros, op. cit., 53.

49 Archivo Histórico Nacional de Chile. Contratos en Europa. 1884-1889. Decreto del 24/25 de noviembre de 1886, firmado por A. Blest Gana, ministro de Chile en Francia. Vol. 554. Fondo Justicia, Culto e Instrucción Pública. 
les) en las escuelas públicas, y el ramo de gimnasia (8 horas semanales) en la Escuela Normal de Preceptores de Santiago ${ }^{50}$.

- Vicetas Krzirwan y Johannes Türkes, provenientes de Dresden, contratados como maestros de la Escuela Normal de Preceptores de Chillán.

Entre la gran cantidad de profesoras que llegaron a Chile, destacamos las siguientes: Johanna Gremler ${ }^{51}$, contratada como directora para la Escuela Normal de Concepción; Antonia Güldenpffenning, Therese Kühlein y Magdalena y María Schöffer, todas contratadas para ejercer en la Escuela Normal de Preceptoras de Santiago en calidad de profesoras; Amelia Witowski, celebra su contrato en la ciudad de Leipzig, en 1884, para ejercer por seis años como profesora de Historia Universal, lengua francesa y piano; Ana Zauvadsky, profesora de canto y labores de mano (bordado), contratada en 1887 para ejercer en la Escuela Nacional de Preceptoras del sur; Wilhelmine von Kalchberg, contratada como profesora de matemáticas y ciencias naturales para ejercer en la Escuela Normal de Santiago ${ }^{52}$; Thérese Adametz, quien llegó a ser directora de la Escuela de Preceptoras de Santiago, firmó contrato el 2 de agosto de 1884, en Viena, ante José Abelardo Núñez. Ejercía como subdirectora del Instituto Real e Imperial denominado Offizierstöchter-Erziehungsinstitut (Instituto de Educación de hijas de oficiales imperiales y reales), en Hernals. Había ejercido también durante seis años en las prestigiosas escuelas de Bürgerschulenclassen ${ }^{53}$; Isabel Bongard Cordes, nacida en Arnsberg, Westfalia, en 1854, estudió en la Renania, en Bonn y en Colonia. Había ejercido además en la Escuela Normal de Berlín. Llegó a Chile por especial encargo de José Abelardo Núñez en 1884, desempeñándose primero como subdirectora en la Escuela Normal del Sur y más tarde, en 1890, pasó a ejercer el cargo de directora de la Escuela de Preceptoras de La Serena ${ }^{54}$.

Junto con estas destacadas preceptoras habría que seguir las trayectorias biográficas de otras numerosas profesoras que desarrollaron una abnegada y notable docencia que permitió un desarrollo prestigioso de la enseñanza femenina en Chile, un país periférico y lejano a los principales circuitos culturales europeos de donde provenían.

Posterior a la creación de la primera Escuela Normal de Preceptores (1842) y luego de la Escuela Normal de Preceptoras de Santiago (1853), la Escuela Normal de Chillán (1871) y la Escuela Normal Isabel Bongard de La Serena (1874), estas últimas bajo la dirección de José Abelardo Núñez en el cargo de inspector general de Escuelas Normales. Al expandirse hacia el sur, se establecen la Escuela Normal de Valdivia (1896), la Escuela Normal de Puerto Montt (1904), la

\footnotetext{
50 Ibíd.

51 Ibíd. Documento n. 137 de la Legación de Chile en Berlín, 15 de diciembre de 1887.

52 Archivo Histórico Nacional de Chile. Contratos en Europa. 1884-1889. Decreto del 24/25 de noviembre de 1886. op. cit.

53 Ibíd.

54 Adriana Alfonso y Susana Pacheco, Elisabeth-Isabel Bongard. Migrante y protagonista de la Reforma Educacional alemana en Chile (La Serena: Editorial Universidad de La Serena, 2011), 114.
} 
Escuela Normal de Victoria (1906), la Escuela Normal de Angol (1908) y la de Ancud (1931) ${ }^{55}$.

En el primer Congreso Nacional Pedagógico, en 1889, José Abelardo Núñez, al intervenir en su calidad de inspector general de Instrucción Primaria, se refirió a los relevantes progresos que la educación primaria había ido alcanzando en el país después de un prolongado estancamiento en estas materias.

(...) Después de medio siglo, nuestra organización escolar, los métodos i enseñan$z a$, no habían recibido los mejoramientos i modificaciones que debían poner nuestras escuelas en armonía con los principios de la pedagogía moderna i con el progreso alcanzado por los países que marchan a la cabeza del movimiento intelectual del mundo $0^{56}$.

En este sentido, la reforma educacional traía consigo un ineludible proceso de modernización de las prácticas pedagógicas del profesorado, lo cual implicaba imperativamente "formar buenos maestros i construir adecuados locales de escuelas" ${ }^{57}$. Sin embargo, durante la segunda parte del siglo xIX, investigaciones realizadas por el investigador Omar Turra permiten afirmar que los preceptores constituían un grupo de educadores diversos: "los normalistas", educadores y educadoras que habían realizado sus estudios en una Escuela Normal; "los propietarios", que si bien no habían asistido a una Normal rindieron un examen de acuerdo con las exigencias de la misma; y "los interinos", que realizaban docencia sin haber rendido el examen que los habilitara como "propietarios" 58 .

En estas circunstancias se destaca el planteamiento de José María Muñoz, uno de los primeros estudiantes normalistas seleccionados para viajar a Alemania en 1884, quien valora de manera positiva el énfasis en el carácter científico de la pedagogía. Esto sin duda está teñido por la atmósfera positivista cientificista empiricista que envolvía los ambientes de educación superior en Europa occidental, escenario en el cual todas las disciplinas deseaban ser ciencia, incluida la filosofía trascendental ${ }^{59}$. Husserl planteaba que el aprendizaje científico nunca consiste en recibir pasivamente materias de otro espíritu; sino que siempre estriba en inactividad propia, en el íntimo reproducir, según fundamentos y secuelas, las evidencias racionales que obtuvieron los espíritus creativos. Por tanto, no es que la pedagogía haya sido en ese ambiente una ciencia imperfecta; el problema era mayor: aún no era ciencia rigurosa ${ }^{60}$.

\footnotetext{
55 Conejeros Maldonado, op cit., 57.

56 Mario Monsalve Bórquez, “--I el silencio comenzó a reinar". Documento para la historia de la instrucción primaria. 1840-1920. (Santiago: UC Blas Cañas y Centro de Investigación Diego Barros Arana: 1998), 78.

57 Ibíd., 187.

58 Omar Turra Díaz y Angélica Torres Vásquez, "Instrucción pública y demanda por preceptores normalistas en la Araucanía del siglo xix", Revista Historia de la Educación Latinoamericana, n. ${ }^{\circ} 28$ (2017), 13.

59 Edmund Husserl, La filosofía, ciencia rigurosa (Madrid: Encuentro, 2009), 9.

60 Ibíd., 12.
} 


\section{Formación de profesores en territorio indígena mapuche}

El progresivo avance del Estado de Chile hacia territorio mapuche comenzó a diseñarse a comienzos de la década de 1850 y se materializó entre 1881 y 1883, cuando el Ejército de la Guerra del Pacífico ingresó a la Frontera (sociedad chilena / mundo mapuche) ubicada al sur del río Biobío. En el caso de Chile, la resistencia cultural y política de parte del pueblo mapuche impidió que la colonia se consolidara en su territorio. Esta realidad obligó a la corona española a financiar un ejército profesional y pagado en las primeras décadas del siglo xvII, durante el gobierno de Alonso de Ribera. De este modo, los periodos de paz fueron superiores a las circunstancias de beligerancia debido a las complejas relaciones fronterizas de carácter comercial, interétnico, político y cultural ${ }^{61}$. Con el transcurso del tiempo estos vínculos generaron interdependencia económica, con lo cual la guerra de Arauco podría ser interpretada como un constructo mítico elaborado por la historiografía tradicional chilena para reafirmar la idea del mapuche como "indio" salvaje, indómito y guerrero.

Este proceso implicó la instalación de diversos agenciamientos que tuvieron como propósito principal instalar el Estado de Chile en un espacio donde históricamente hubo autonomía del pueblo mapuche, lo que conllevó transformaciones sociales, políticas y culturales al amparo de complejas relaciones interculturales e interétnicas. Es importante aclarar que en este periodo de instalación de la escuela chilena occidental y monocultural, el Estado no está separado de la Iglesia $^{62}$, lo que explica la colaboración entre los grupos dirigentes gobernantes chilenos y representantes de numerosas congregaciones - mayoritariamente católicas-, que se instalan en la Araucanía, que en conjunto con los inmigrantes y colonos europeos, se vieron favorecidos por las políticas exteriores de los Gobiernos post-ocupación del territorio mapuche.

De este modo aparecen dispositivos y mecanismos estatales que aportaron a la configuración de una nueva trama sociocultural en el territorio, entre ellos, la creación de centros urbanos, vías de transporte y de comunicación y el establecimiento de una red de escuelas públicas que tenía como propósito alfabetizar a la población mapuche y no mapuche del territorio ocupado ${ }^{63}$. En este sentido, coexistieron en la región de la Araucanía dos modelos de formación de educadores, que se constituyeron en prototipos educacionales muy diferentes: uno propio de la racionalidad liberal, positivista y occidental, cuyo propósito principal fue la instalación de una escuela monocultural, para lo cual se necesitaba formar a preceptores que enseñaran en este tipo de escuela, privilegiando el idioma castellano; y por otro lado, las prácticas formativas que mantuvieron algunos agentes mapuche en las comunidades indígenas que se configuraron en esta nueva

61 Carlos Ortiz Aguilera, "Distribución territorial de las Reguas Mapuches a principios del siglo XVII (1600-1620)", Tiempo y Espacio, n. ${ }^{\circ} 18$ (2007), 8.

62 La separación entre el Estado de Chile y la Iglesia católica se concretará en 1925, con la promulgación de la Constitución de la República.

63 Omar Turra Díaz y Angélica Torres Vásquez, "Instrucción pública y demanda por preceptores normalistas en la Araucanía del siglo XIx", Revista Historia de la Educación Latinoamericana, n. ${ }^{\circ} 28$ (2017): 129-148. 
realidad sociopolítica generada post ocupación de la Araucanía, principalmente entre 1881 y 1930. En este escenario se ve afectado el mogen, entendido como vida o tener vida, concepto integral mapuche que se refiere a diversos niveles de la vida y de estar con vida, estar sano, lo que incluye la dimensión salud, el sustento (mogelün), estar en relación con los demás. Por otro lado, refiere también a existencia, o condiciones para la vida, como se expresa en Pelan ñi mogeaqel faw, pelan küzaw64.

Ya en las primeras décadas del siglo $\mathrm{xx}$, Chile contaba con una red de escuelas operando en ciudades, pueblos y lugares remotos. El Estado había invertido recursos en mejorar su oferta: construyó una infraestructura cada vez más especializada, proveyó de textos y materiales, uniformó los métodos de enseñanza y fundó Escuelas Normales en provincias ${ }^{65}$.

En definitiva, la instalación de la escuela chilena en territorio indígena afectó los propios procesos formativos dentro de la sociedad mapuche, los kimches (personas con conocimiento ancestral) son reemplazados por profesores y escuelas, las rogativas mapuche (gijatun o kamarrikun) comienzan a desarrollarse con menos frecuencia y los estudiantes al permanecer internos en algunos periodos no participarán de estas importantes ceremonias. El saber de la nueva cultura germana, chilena y occidental comienza a desplazar los saberes mapuche ${ }^{66}$. El propio aspecto valórico expresado en el concepto feyentun zugu, aquel valor que le otorga una persona a las orientaciones entregadas por los füshakeche (anciano o anciana con características de sabio), que permiten la comprensión del legado cultural ancestral indígena, comienza a ser eclipsado por los saberes hegemónicos de la escuela chilena con influencia germana.

En definitiva, la realidad que se fue construyendo socialmente con la presencia de diversas culturas después de la ocupación forzosa del Estado de Chile del territorio mapuche en la segunda mitad del siglo xix favoreció un proceso de relocalización y pérdida de los asentamientos históricos del pueblo mapuche, lo que impactó significativamente en su bienestar integral y lo fue constituyendo en una población minoritaria en su propio territorio.

\section{CONCLUSIÓN}

Las reformas impulsadas a fines del siglo xIx para modificar el sistema de formación del preceptorado en Chile encontraron resistencia en ciertos grupos conservadores de las elites gobernantes de la sociedad chilena, sobre todo cuando los profesores germanos aumentaron su presencia en el sistema de instrucción primaria, tanto en las Escuelas Normales como en las escuelas y liceos.

64 Félix de Augusta, Lecturas Araucanas (Temuco, Kushe, 1991), 145.

65 Macarena Ponce de León Atria, "La llegada de la escuela y la llegada a la escuela. La extensión de la educación primaria en Chile, 1840-1907", Revista Historia n. ${ }^{\circ} 43$ (2010): 1-38.

66 Daniel Quilaqueo Rapimán, “Saberes educativos mapuches: un análisis desde la perspectiva de los kimches”, Polis, revista latinoamericana, . $^{\circ} 26$ (2010):20. 
La presencia sistemática de educadores alemanes en Chile no pasó inadvertida. De hecho, los maestros y maestras que llegaron asumieron inmediatamente con mucha vocación las tareas encomendadas, prestando sus principales servicio en la red de colegios del sistema público. Su rápida instalación en el centro-sur de Chile se vio favorecida por las políticas favorables a la inmigración alemana iniciadas a mediados del siglo xIx por el presidente de la República Manuel Montt.

La presencia de una gran cantidad de preceptores alemanes generó desconfianza en destacados intelectuales y hombres públicos, quienes desde las diferentes posiciones que ocupaban fueron levantando un discurso nacionalista, que se agudizó durante 1910, año en que la República de Chile conmemoró el primer centenario de la independencia política ${ }^{67}$. Estas críticas a la presencia de extranjeros en Chile, en particular de europeos, fue llevada una dimensión más radical por el Dr. Julio Valdés Canje (seudónimo utilizado por el escritor Alejandro Venegas), , quien tachó a los grupos dirigentes de Chile de un "excesivo cosmopolitismo y a la vez un desprecio por lo nacional", lo cual estaba generando un galopante deterioro de la "identidad criolla chilena", la que, a su vez, según este autor, "tenía a las escuelas normalistas como su principal estandarte" ${ }^{68}$. Fue especialmente crítico con la formación de profesores secundarios, quienes, a su juicio, asumían la vocación de la enseñanza no como un fin noble y elevado que permitiera contribuir al engrandecimiento de la patria, sino como un medio para ganar dinero: por tanto, consideraba preciso desaparecer a los instructores y reemplazarlos por los educadores, y para ello se necesitaba un cambio profundo en la formación de preceptores y preceptoras ${ }^{69}$.

No obstante, fue la obra del escritor masón Eduardo de la Barra La vida nacional. El embrujamiento alemán (1899), la que lideró la crítica a los maestros y maestras alemanes por su labor pedagógica en Chile, su abundante presencia en el sur del país, tanto en el ámbito laico, como en el campo religioso ${ }^{70}$. En este último caso se debe añadir la solicitud que hizo el Estado de Chile a la Congregación de los Capuchinos de Baviera para que contribuyeran con la educación hacia los indígenas mapuche a fines del siglo xIX para "civilizarlos" y "pacificarlos"71. De hecho, según Jean-Pierre Blancpain, la empresa alemana en territorio chileno fue más nefasta y destructora que otras, porque fue apoyada oficialmente por el Estado, en consecuencia, legitimada en su origen ${ }^{72}$. En este sentido, diferentes

67 Cristian Gazmuri Riveros, Testimonios de una crisis, Chile: 1900-1925 (Santiago: Editorial Universitaria, 1980), 49.

68 Alejandro Venegas Carus, Sinceridad. Chile íntimo en 1910 (Santiago: Biblioteca Fundamentos de la Construcción de Chile/Pontificia Universidad Católica de Chile), 225.

69 Ibíd., 226.

70 Eduardo de la Barra. La vida nacional. El embrujamiento alemán (Roma: Establecimientos Poligráficos), 121.

71 Debemos recordar que, entre 1833 (primera Constitución de la República) y 1925 (segunda Constitución) el Estado de Chile no estuvo separado de la Iglesia católica, lo que facilitó la presencia activa de diversas congregaciones religiosas. O sea, cuando actuaban capuchinos, salesianos y franciscanos, era el Estado el que actuaba. No ocurrió así en otros territorios: por ejemplo, las investigaciones que ha realizado María Andrea Nicoletti desde la Universidad Nacional de Río Negro han demostrado suficientemente el conflicto entre la congregación salesiana y las escuelas del Estado en la Patagonia.

72 Blancpain, op. cit., 158. 
historiadores han estimado que estos dichos son exagerados porque no atienden los aportes de los maestros y maestras alemanes que llegaron a Chile.

Asimismo, a la luz de los diferentes documentos revisados, existe evidencia suficiente para afirmar que la presencia densa e influyente de la cultura alemana desde fines del siglo xIx hasta la primera mitad del siglo xx, no solo se materializó en la gestión y docencia en las Escuelas Normales, sino en la creación de colegios alemanes en espacios urbanos emergentes. En este último punto es interesante relevar la fundación en 1887 del Colegio Alemán de Temuco, el cual aparece seis años después de la fundación de Temuco y los 130 años que en 2017 conmemora coinciden con la creación de la Provincia de Cautín, cabecera política y administrativa de la actual región de la Araucanía. Junto con ello, se debe destacar la presencia de los capuchinos bávaros, fundadores del magisterio de la Araucanía, ente que aún hoy sostiene la educación cooperativa del estado más grande de Chile. El 6 de noviembre de 1895 se embarcaron en Hamburgo tres padres y un hermano lego: el P. Anselmo de Kamin (futuro párroco de Boroa y fundador de Padre Las Casas), el P. Félix José de Augusta (médico judío alemán de 35 años) el P. Tadeo de Wiessent (famoso por la aplicación del método hidroterápico) y el hermano Sérvulo de Gottmannshofen. Por tanto, la gravitancia de la presencia alemana se visualiza en los diferentes niveles del sistema escolar, desde prekinder hasta la educación superior.

Otro aspecto relevante a considerar es el choque intercultural que se produjo a partir de la intersección de tres culturas distintas presentes en el territorio de la Araucanía: alemanes, chilenos y mapuches, cuya coexistencia tuvo diferentes ciclos, siendo la escuela el agente mediador. En varias circunstancias muchos profesores provenientes de Baviera o Prusia no estaban preparados para asimilar y respetar adecuadamente los códigos socioculturales propios de las identidades locales en la Araucanía y de la sociedad sudamericana.

Del mismo modo, a partir de la reforma promovida de las escuelas normales y la llegada de la pedagogía alemana, la enseñanza chilena comenzó una transición hacia una pedagogía más "moderna", iniciándose en la investigación aplicada, la promoción de la disciplina en las Escuelas Normales y la aparición de disciplinas hasta entonces postergadas del currículum prescriptivo: ciencias físicas, biología, botánica, música, trabajos manuales y gimnástica. Por tanto, aparece una nueva didáctica, nuevas asignaturas y nuevas visiones del mundo.

Se visualiza una notoria influencia de la epistemología pedagógica de Herbart en el discurso curricular de los preceptores alemanes en Chile. Los prototipos, lecciones-modelo, destacan la reflexión en la acción, la importancia de la sabiduría práctica, de la experiencia y la observación persistente del mundo de la vida (lebenswelt). El término que resume esta cuestión es "pedagogía científica", cuya retórica fue el eje del discurso pedagógico en la primera mitad del siglo xx en los principales congresos educacionales que se llevaron a cabo. Es el inicio de la profesionalización del profesorado en Chile.

Valentín Letelier, José Abelardo Núñez y Claudio Matte fueron los principales propagadores de la reforma de la educación en Chile, promoviendo las bondades y supuestos "beneficios" del modelo pedagógico alemán, que a su vez fue un proto- 
tipo para otros Estados de América Latina. Por tanto, ellos instalan un discurso proclive a la idea de profesionalización de la formación del preceptorado, de tal modo que se superen las características propias del modelo francés. El paradigma fue el Real Gimnasio alemán. Esta situación implicó la circulación de intelectuales chilenos en Alemania y, posteriormente, a raíz de esas visitas, la circulación de alemanes en Chile. Alemania se transformó, por consiguiente en un modelo de Estado-nación al implementar la transferencia del saber científico en el perfeccionamiento de su educación, tanto en la escuela como en el ejército. Podemos concluir que los triunfos de Alemania en la guerra franco-prusiana y de Chile en la Guerra del Pacífico potenciaba un imaginario de relación del tipo Weltpolitik.

No obstante lo anterior, la presencia de esta pedagogía en las Escuelas Normales no evidencia un esfuerzo de parte de los preceptores por contextualizar los diseños de la enseñanza y su posterior concreción en el aula, por tanto, en varias circunstancias aparece la dicotomía de siempre de modo acentuado: distancia entre teoría y realidad, al amparo de una noción monárquica de la disciplina, muy influenciada por el legado de la Alemania de Bismarck.

Las Escuelas Normales fueron el escenario donde se forjó la interculturalidad y a la vez se produjo un tenso proceso de transferencia ideológica y cultural que vivió la educación chilena a fines del siglo xIx y comienzos del siglo xx, cuyos principales referentes fueron los pedagogos alemanes. Esta realidad influyó de modo decisivo no solamente en los proyectos formativos y reglamentos de las escuelas normales, sino también en todo el sistema escolar chileno, lo que a su vez fue consolidando un modelo de escuela monocultural occidental que adquirió un carácter hegemónico en desmedro de las ancestrales prácticas de formación de los mapuche (kimeltuwun), en el caso particular del territorio mapuche histórico (que hoy incluye cuatro regiones del centro sur de Chile).

La discusión sobre la pertinencia del modelo pedagógico alemán implementado en Chile queda abierta, en pleno proceso conmemorativo de su primer centenario como país libre e independiente. El modelo pedagógico alemán exógeno dividió los posicionamientos de los teóricos educacionistas de la época, algunos de los cuales estaban embrujados con un fuerte nacionalismo y chilenismo, posición que tampoco reclamó considerar a las culturas originarias de Chile, sino todo lo contrario: volver a colonizarlas, esta vez de modo definitivo.

\section{FUENTES}

Archivo Histórico Nacional de Chile. Contratos en Europa. 1884-1889. Decreto del 24/25 de noviembre de 1886, firmado por A. Blest Gana, ministro de Chile en Francia. Vol. 554. Fondo Justicia, Culto e Instrucción Pública.

Archivo Histórico Nacional de Chile. Contratos en Europa, 1884-1889. Documento n. ${ }^{\circ} 137$ de la Legación de Chile en Berlín, 15 de diciembre de 1887.

Archivo Nacional de Chile (АNCH), Santiago-Chile. Ministerio de Educación (MEDU), Fondo Instrucción Primaria.

Archivo Regional de la Araucanía (ARA). Temuco-Chile. Dirección de Bibliotecas, Archivos y Museos. Fondo de Intendencia de Cautín. 
Biblioteca Nacional de Chile (вNCH), Santiago-Chile. Sección Hemeroteca, Fondo Bibliográfico, sala Medina. El Monitor de las Escuelas Primarias.

Biblioteca Nacional de Chile (BNCH), Santiago de Chile. José Toribio Medina, Fondo Histórico y Bibliográfico José Toribio Medina, vol. 8, Documento 113.

\section{REFERENCIAS}

Alfonso, Adriana y Susana Pacheco. Elisabeth-Isabel Bongard. Migrante y protagonista de la Reforma Educacional alemana en Chile. La Serena: Editorial Universidad de La Serena, 2011.

Almeida da Silva, Arnelice. Edgar Quinet e a filosofia da Revolução Francesa". Revista de História, n. ${ }^{\circ} 146$ (2002): 223-266.

Amunátegui Reyes, Miguel. “Cómo y por qué se suprimió el castigo del 'guante' en los colegios del Estado". Revista Chilena de Historia y Geografía. n. 39 (1920): 16-34.

Ávalos Davidson, Beatrice. "La profesión docente en Chile a más de 150 años de su primera institucionalización", en Relatos para la educación en el bicentenario Santiago: Universidad de Chile, Universidad Católica, 2010, 152.

Blancpain, Jean Pierre. Los alemanes en Chile (1816-1945). Santiago: Universitaria, 1985.

Caiceo Escudero, Jaime. “Orígenes y principales exponentes del laicismo, en su vertiente educativa, en Chile", Revista Historia da Educação n. ${ }^{\circ} 51$ (2017): 333-350.

Cassigoli, Roxana. "Sobre la presencia nazi en Chile". Acta sociológica, n. ${ }^{\circ} 61$ (2013): 164.

Celis Muñoz, Luis. Historia de la educación chilena, siglos XVI al XIx. Santiago: Universidad de Los Lagos, 2014.

Conejeros Maldonado, Juan. La influencia cultural francesa en la educación chilena 1840-1880. Santiago: Universidad Católica Silva Henríquez, 1999.

Château, Jean. Les Grands pédagogues. Paris: Puf, 1974.

De Augusta, Félix. Lecturas Araucanas. Temuco: Kushe, 1991.

De la Barra, Eduardo. La vida nacional. El embrujamiento alemán. Roma: Establecimientos Poligráficos, 1899.

Figueroa Cerna, Carolina; Silva Torrealba, Benjamín. "La demanda política de un actor educativo: el visitador de escuelas primarias Ramón López Pinto (Tarapacá, norte de Chile 18891907)", Cuadernos de Historia, n.o 34 (2011):1-29.

Foucault, Michel. Vigilar y castigar. Nacimiento de la prisión. México: Siglo XXI, 1975.

Gazmuri Riveros, Cristian. Testimonios de una crisis, Chile: 1900-1925. Santiago: Universitaria, 1980.

Hargreaves, Andy. Cuatro edades del profesionalismo y del aprendizaje profesional, en La formación de profesores. Perspectiva y experiencias, ed. por B. Ávalos \& M. E. Nordenflycht. Santiago: Aula XXI/Santillana, 1999.

Husserl, Edmund. La filosofía, ciencia rigurosa. Madrid: Encuentro, 2009.

Jaksic Andrade, Iván. "Valentín Letelier: the Influence of positivism on Chilean Educational Thought", Pensamiento Educativo, n. ${ }^{\circ} 46$ (2010): 127-145.

Krebs Wilckens, Ricardo; Gazmuri Riveros, Cristian. La Revolución francesa y Chile. Santiago: Editorial Universitaria, 1990.

Labarca, Amanda. Historia de la enseñanza en Chile. Santiago: Imprenta Universitaria, 1939.

Mansilla Sepúlveda, Juan y Claudia Huaiquián Billeke. Logos y techné. Metodología de la investigación científica. Temuco: Universidad Mayor, 2015.

Mondragón Velázquez, Rafael. "Anticolonialismo y socialismo de las periferias. Francisco Bilbao y la fundación de La Tribune des Peuples". Latinoamérica. Revista de Estudios Latinoamericanos, n. 56 (2013): 105-139.

Monsalve Bórquez, M. "--I el silencio comenzó a reinar". Documento para la historia de la instrucción primaria. 1840-1920. Santiago: UC Blas Cañas y Centro de Investigación Diego Barros Arana, 1998.

Mora García, José; Soto Arango, Diana y Lima Jardilino José. “La historia de la educación en América Latina: Contribución y aportes de la Sociedad de Historia de la Educación Latinoamericana SHela (1994-2015) Revista Historia da Educação, n. ${ }^{\circ}$ 51, vol. 21 (2017): 351-375. 
Mora Rodríguez, Arnoldo. “En el bicentenario de su nacimiento: Víctor Hugo y la estética del romanticismo". Revista Comunicación, n. ${ }^{\circ}$ 2, vol. 12 (2002): 1-7.

Muñoz Gomá, María y Cifuentes, Abdon. "Visión de futuro. La orientación práctica de la enseñanza (1836-1928)", Pensamiento Educativo, n. ${ }^{\circ} 34$ (2004): 289

Núñez Prieto, Iván. "La formación de los docentes. Notas históricas", en Beatrice Ávalos, Profesores para Chile. Historia de un proyecto. Santiago: Ministerio de Educación, 2002.

Núñez Prieto, Iván. "Escuelas Normales. Una historia larga y sorprendente. Chile (1842-1973)". Pensamiento Educativo, n. ${ }^{\circ} 46-47$ (2010): 133-150.

Núñez Murúa, José Abelardo Estudios sobre educación moderna: Organización de escuelas normales. Santiago: Imprenta de la Librería Americana, 1883.

Núñez Murúa, José Abelardo. Congreso Nacional Pedagógico, resumen de las discusiones, actas y memorias, publicación oficial. Santiago: Imprenta Nacional, 1890.

Ocampo López, Javier. “Domingo Faustino Sarmiento. El Presidente de Argentina 'Maestro de América'", Revista Historia de la Educación Latinoamericana, n. ${ }^{\circ} 2$ (2000): 1-25.

Ponce de León Atria, Macarena. “La llegada de la escuela y la llegada a la escuela. La extensión de la educación primaria en Chile, 1840-1907", Revista Historia n. ${ }^{\circ} 43$ (2010): 1-38.

Ortiz Aguilera, Carlos. "Distribución territorial de las Reguas Mapuches a principios del siglo XviI (1600-1620)", Revista Tiempo y Espacio, n. ${ }^{\circ} 18$ (2007): 1-16.

Quilaqueo Rapimán, Daniel. “Saberes educativos mapuches: un análisis desde la perspectiva de los kimches", Polis, revista latinoamericana, n. ${ }^{\circ} 26$ (2010):1-22.

Serrano, Sol, Macarena Ponce de León y Francisca Rengifo. Historia de la Educación en Chile (18102010), t. II. Santiago: Taurus, 2012.

Silva Torrealba, Benjamín. "Historia social de la educación chilena", en Instalación, auge y crisis de la reforma alemana 1880 a 1920. Agentes escolares, t. 1. Santiago: Ediciones Universidad Tecnológica Metropolitana, 2015, 43.

Turra Díaz, Omar y Angélica Torres Vásquez. "Instrucción pública y demanda por preceptores normalistas en la Araucanía del siglo xix". Revista Historia de la Educación Latinoamericana, n. ${ }^{\circ} 28$ (2017): 129-148.

Venegas Carus, Alejandro. Sinceridad. Chile íntimo en 1910. Santiago: Biblioteca Fundamentos de la Construcción de Chile/Pontificia Universidad Católica de Chile.

Vergara Quiroz, Sergio, estudio, selección y notas. Manuel Montt y Domingo F. Sarmiento Epistolario 1833-1888. Fuentes para la historia de la República, vol. xIv. Santiago: Dirección de Bibliotecas, Archivos y Museos-dibam y Centro de Investigación Barros Arana, 1999.

Vial Correa, Gonzalo. Historia de Chile (1891-1920), vol. 1, La sociedad chilena en el cambio de siglo. Santiago: Editorial Santillana, 1981.

Vial Correa, Gonzalo. Historia de Chile, t. II. Santiago: Portada, 1981, 239.

Villalobos Rivera, Sergio. Origen y ascenso de la burguesía chilena. Santiago: Editorial Universitaria, 1987.

Zoraida Vázquez, Josefina. Historia de la historiografía. México: Ateneo, 1978.

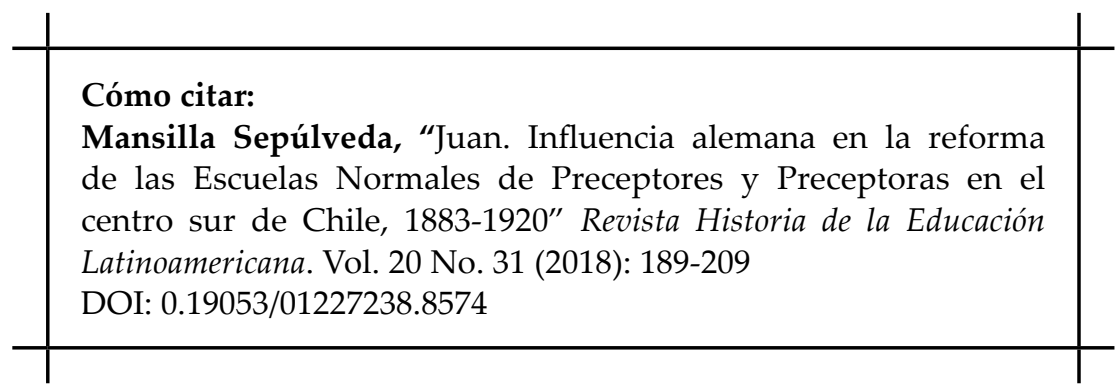




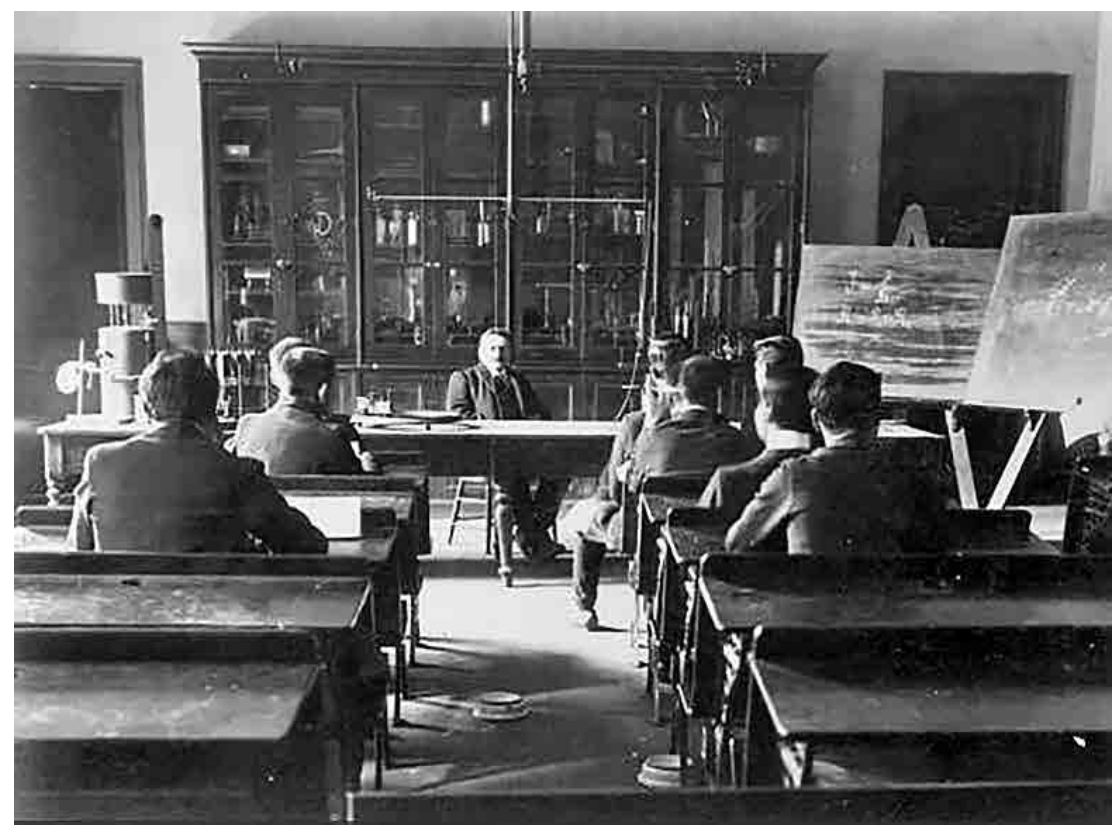

Fuente: www.memoriachilena.cl 